\title{
Uji Kesahihan dan Keandalan Kuesioner Childhood Asthma Control Test versi Indonesia pada Anak Usia 4-11 Tahun
}

\author{
Cynthia Utami, Mardjanis Said, Nastiti Kaswandani, Dwi Putro Widodo \\ Departemen Ilmu Kesehatan Anak Fakultas Kedokteran Universitas Indonesia/RS Dr. Cipto \\ Mangunkusumo, Jakarta
}

\begin{abstract}
Latar belakang. Childhood Asthma Control Test (CACT) merupakan kuesioner penilaian terkendalinya asma pada anak yang cepat dan mudah digunakan. Di Indonesia, penggunaan CACT masih terbatas karena kendala bahasa dan budaya. Sampai saat ini, belum ada kuesioner CACT versi Indonesia (terjemahan CACT ke dalam bahasa Indonesia) yang terbukti sahih dan andal.

Tujuan. Mengetahui kesahihan (validity) dan keandalan (reliability) kuesioner CACT versi Indonesia.

Metode. Menerjemahkan tujuh pertanyaaan kuesioner CACT menjadi kuesioner CACT versi Indonesia. Studi potong lintang dilakukan terhadap 66 subjek usia 4-11 tahun yang dipilih secara konsekutif. Semua subjek menjalani uji fungsi paru dan pemeriksaan peak expiratory flow berkala. Analisis statistik menggunakan uji Cronbach's $\alpha$ dan uji korelasi Pearson/ Spearman.

Hasil. Rerata usia subjek penelitian 7,89 tahun (5,25 -11,83) tahun dengan proporsi jenis kelamin laki-laki lebih tinggi dibandingkan perempuan. Sebagian besar subjek penelitian yaitu 60,4\% memiliki status asma tidak terkendali (nilai kuesioner CACT $\leq 19$ ). Kuesioner CACT versi Indonesia mempunyai keandalan (Cronbach's $\alpha$ 0,762) dan kesahihan konstruksi ( $r=0,384-0,545)$ yang baik. Tidak terdapat korelasi bermakna antara kuesioner CACT versi Indonesia dengan nilai $\mathrm{FEV}_{1}(\mathrm{r}=-0,024 ; \mathrm{p}=0,846)$ dan nilai variabilitas mingguan PEF ( $r=-0,218 ; \mathrm{p}=0,079)$.

Kesimpulan. Kuesioner CACT versi Indonesia mempunyai kesahihan dan keandalan yang baik untuk menilai terkendalinya asma. Kuesioner ini tidak mempunyai korelasi dengan uji fungsi paru sehingga CACT tidak dapat menggantikan peran uji fungsi paru sebagai salah satu komponen penilaian terkendalinya asma.
\end{abstract}

Sari Pediatri 2014;16(2):103-9.

Kata kunci: childhood asthma control test, uji fungsi paru, peak expiratory flow

\footnotetext{
Alamat korespondensi:

Dr. Nastiti Kaswandani, SpA (K), Dr. Cynthia Utami, Sp.A. Divisi Respirologi Anak RSUPN Dr. Cipto Mangunkusumo. Jl. Diponegoro 71, JAKPUS. Telp. (021) 3916043,3148930. E-mail: cyntia_utami@ idai.or.id
}

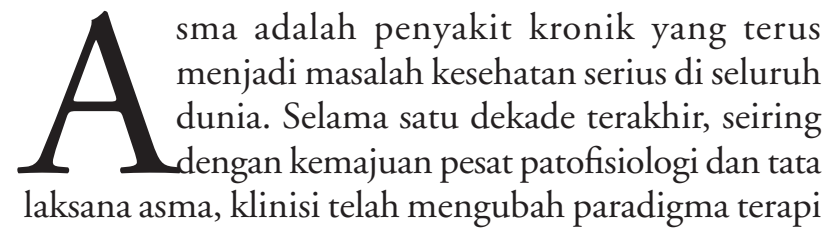


asma. Fokus terapi asma tidak hanya menatalaksana serangan asma saja, tetapi mencapai terkendalinya asma yang adekuat. ${ }^{1,2}$

Sampai saat ini, belum ada baku emas untuk menilai terkendalinya asma. Instrumen berupa kuesioner yang berbasis penilaian pasien dilaporkan memberikan informasi cepat dan akurat mengenai status terkendalinya asma. Salah satu kuesioner terkendalinya asma pada anak yang telah teruji kesahihan dan keandalannya adalah kuesioner Childhood Asthma Control Test (CACT). Kuesioner ini diperuntukkan untuk anak usia 4-11 tahun, berisi 7 pertanyaan yang diisi secara mandiri oleh anak dan orangtua atau pengasuh. Penggunaan kuesioner dipengaruhi oleh tata bahasa dan profil budaya masyarakat. Sampai saat ini, belum ada laporan penggunaan CACT di Indonesia. ${ }^{3,4}$

Tujuan penelitian kami adalah melakukan uji kesahihan dan keandalan dari kuesioner CACT versi Indonesia berbahasa Indonesia. Kuesioner CACT versi Indonesia diharapkan dapat menjadi alat ukur yang baik dan mudah digunakan secara umum.

\section{Metode}

Kami melakukan validasi bahasa pada kuesioner CACT versi asli bahasa Inggris ke bahasa Indonesia setelah mendapat ijin dari Glaxo Smith Kline sebagai pemegang hak paten CACT. Proses validasi bahasa meliputi forward translation, diskusi, back translation, diskusi, dan uji coba terhadap 5 pasien. ${ }^{5}$ Kata asma dalam kuesioner dilengkapi dengan istilah lain, yaitu bengek, mengi, mengguk, isak, sesak, nyesek, mengok, mengek, ampeg. Sementara itu, kata ngik-ngik dilengkapi dengan istilah mencicit/mencuit sesuai dengan kuesioner International Study of Asthma and Allergies in Childhood (ISAAC) dalam bahasa Indonesia. ${ }^{6}$

Penelitian dengan desain potong lintang dilakukan di Poliklinik Respirologi Departemen Ilmu Kesehatan Anak Rumah Sakit Dr. Cipto Mangunkusumo (RSCM) dan Rumah Sakit Anak dan Bunda Harapan Kita (RSAB Harapan Kita) pada bulan Januari 2012Mei 2013. Kriteria inklusi adalah anak berusia 4-11 tahun dengan diagnosis asma oleh dokter minimal satu bulan, mampu melakukan pemeriksaan spirometri dan peak expiratory flow, serta menyatakan kesediaan untuk ikut serta dalam penelitian ini. Anak dengan gangguan mental dan dalam serangan asma berat tidak diikutsertakan dalam penelitian.

Orangtua subjek diberikan penjelasan mengenai penelitian dan menandatangani surat informed consent. Kuesioner CACT versi Indonesia berisi tujuh pertanyaan, yaitu empat pertanyaan diisi oleh subjek dan tiga pertanyaan diisi oleh orangtua. Pengisian kuesioner untuk anak dan orangtua dilakukan dengan peneliti pendamping. Sebelum pengisian kuesioner, peneliti menjelaskan secara singkat tentang pengertian asma dijelaskan sesuai dengan definisi asma menurut Pedoman Nasional Asma Anak (PNAA) tahun 2004. Peneliti juga melakukan wawancara terbuka untuk memastikan anak dan orangtua telah memahami pengertian asma. Pemeriksaan spirometri (spesifikasi Autospiro AS-7 Minato Japan) dan PEF dipandu oleh peneliti. Subjek penelitian juga dipinjamkan alat peak flow meter (merk Respironics HS755) untuk melakukan PEF setiap pagi dan malam hari selama dua minggu. Hasil peniupan dicatat pada lembar pemantauan yang sudah diberikan sebelumnya. Data PEF yang tidak lengkap yaitu kurang dari tujuh hari akan diekslusi dari penelitian.

Analisis statistik yang dilakukan adalah uji keandalan dengan mengukur nilai internal consistency (Cronbach's ), kesahihan interna (konstruksi) dengan

Pearson correlation. Kedua analisis ini dilakukan baik pada nilai CACT versi Indonesia yang tidak distandarisasi dan yang telah distandarisasi dalam bentuk z-score. Korelasi kuesioner CACT versi Indonesia dengan nilai $\mathrm{FEV}_{1}$ dan variabilitas mingguan PEF dianalisis dengan uji korelasi Spearman. Penelitian ini telah disetujui oleh komisi etik penelitian Fakultas Kedokteran Universitas Indonesia.

\section{Hasil}

Kami melakukan uji coba terhadap kuesioner CACT versi Indonesia yang telah melalui proses validasi bahasa kepada lima pasien asma. Tidak terdapat kesulitan terhadap kata dalam kuesioner sehingga dilanjutkan untuk dilakukan uji kesahihan dan keandalannya. Selama periode penelitian, 70 pasien berhasil diikutsertakan, tetapi terdapat 4 subjek dieksklusi (2 pasien tidak mampu melakukan teknik spirometri dan 2 pasien drop out) sehingga jumlah subjek yang akhirnya diikutsertakan adalah 66 subjek.

Rerata usia subjek penelitian adalah 7,89 tahun $(5,25-11,83)$ tahun dengan proporsi jenis kelamin 
laki-laki lebih tinggi dibandingkan perempuan. Usia termuda yang ikut serta dalam penelitian adalah 5 tahun 3 bulan. Karakteristik sosio demografi dan klinis subjek tertera pada Tabel 1 dan Tabel 2.

Uji keandalan kuesioner dilakukan dengan menggunakan uji Cronbach's $\alpha$. Uji keandalan internal consistency mendapatkan nilai Cronbach's $\alpha$ 0,762 (pada nilai yang tidak terstandarisasi) dan 0,773 (pada nilai yang terstandarisasi dengan nilai $z$-score).

Uji kesahihan yang dilakukan adalah uji kesahihan interna dan eksterna. Kesahihan interna yang diuji adalah kesahihan konstruksi membandingkan nilai masing-masing pertanyaan pada kuesioner CACT versi Indonesia dengan nilai total. Suatu instrumen dinyatakan sahih bila nilai $\mathrm{r}$ (rho) minimal 0,3. Pada penelitian ini, masing-masing pertanyaan pada kuesioner CACT versi Indonesia mempunyai $r>0,3$ (kisaran $\mathrm{r}=0,384-0,545)$ dengan $\mathrm{p}<0,01$ (Tabel 3).

Kesahihan eksterna yang diuji adalah kesahihan kriteria, yaitu membandingkan hasil kuesioner CACT versi Indonesia dengan nilai $\mathrm{FEV}_{1}$ dan nilai variabilitas dari PEF mingguan. Tidak didapatkan korelasi bermakna antara kuesioner CACT versi Indonesia dengan nilai $\mathrm{FEV}_{1}(\mathrm{r}=-0,024 ; \mathrm{p}=0,846)$ (Gambar 1).
Tabel 1. Karakteristik sosio demografis

\begin{tabular}{lcc}
\hline Karakteristik subjek & $\begin{array}{c}\text { Jumlah } \\
(\mathrm{n}=66)\end{array}$ & $\begin{array}{c}\text { Persentase } \\
(\%)\end{array}$ \\
\hline Jenis kelamin & & \\
Laki-laki & 41 & 62,1 \\
Perempuan & 25 & 37,9 \\
Usia (tahun) & & \\
$5-<6$ & 9 & 13,6 \\
$6-<7$ & 15 & 22,7 \\
$7-<8$ & 14 & 21,2 \\
$8-<9$ & 12 & 18,2 \\
$9-<10$ & 5 & 7,6 \\
$10-<11$ & 5 & 7,6 \\
$11-<12$ & 6 & 9,1 \\
Status gizi (IMT/U) & & \\
Kurang & 7 & 10,6 \\
Baik & 40 & 60,6 \\
Lebih & 8 & 12,1 \\
Obesitas & 11 & 16,7 \\
Pendidikan ayah/ibu & & \\
Rendah & 6 & 9,1 \\
Menengah & 26 & 39,4 \\
Tinggi & 34 & 49,5 \\
\hline
\end{tabular}

Tabel 2. Karakteristik medis

\begin{tabular}{|c|c|c|}
\hline Karakteristik subjek & $\begin{array}{c}\text { Jumlah } \\
(\mathrm{n}=66)\end{array}$ & $\begin{array}{c}\text { Persentase } \\
(\%)\end{array}$ \\
\hline \multicolumn{3}{|l|}{ Diagnosis asma } \\
\hline Episodik jarang & 32 & 47,5 \\
\hline Episodik sering & 33 & 50 \\
\hline Persisten & 1 & 1,5 \\
\hline \multicolumn{3}{|l|}{ Lama diagnosis asma } \\
\hline Median & 28 (1-128 bulan) & \\
\hline \multicolumn{3}{|c|}{ Hasil kuesioner CACT versi Indonesia } \\
\hline Median & $19(7-26)$ & \\
\hline Skor >19 (terkendali) & 26 & 39,4 \\
\hline Skor $\leq 19$ ( tidak terkendali) & 40 & 60,6 \\
\hline \multicolumn{3}{|l|}{ Nilai FEV } \\
\hline Rerata & $80 \%(\mathrm{SB} 16,74)$ & \\
\hline$\geq 80 \%$ & 31 & 47 \\
\hline$<80 \%$ & 35 & 53 \\
\hline Nilai variabilitas mingguan PEF & $10,32 \%(\mathrm{SB} 4,93)$ & \\
\hline$<20 \%$ & 65 & 98,5 \\
\hline$\geq 20 \%$ & 1 & 1,5 \\
\hline
\end{tabular}




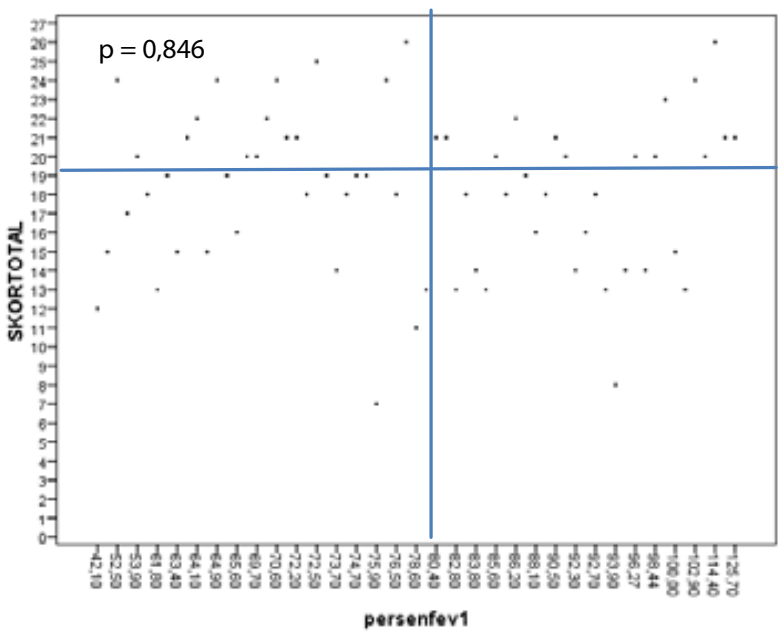

Gambar 1. Korelasi antara kuesioner CACT versi Indonesia dan $\%$ FEV1

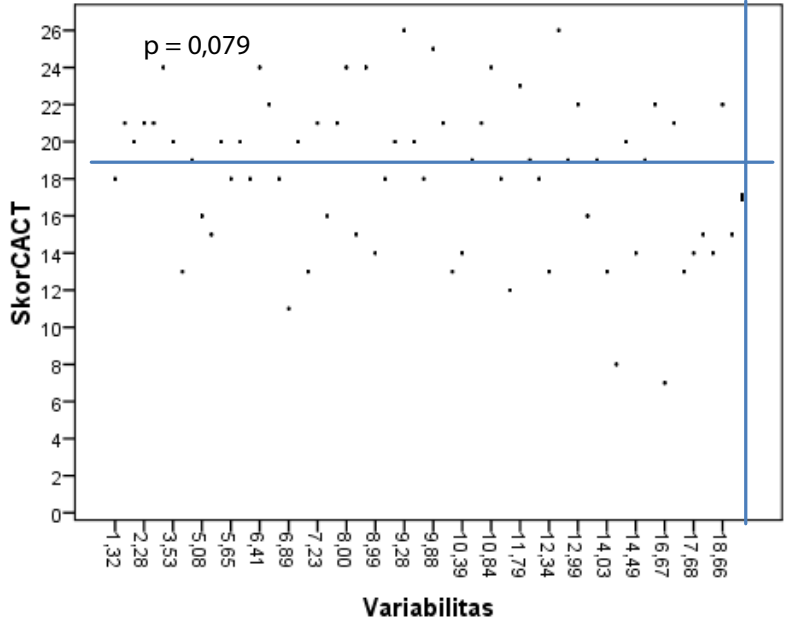

Gambar 2. Korelasi antara kuesioner CACT versi Indonesia dan \% variabilitas PEF

Tabel 3. Hasil uji corrected Pearson correlation coefficient kuesioner

\begin{tabular}{llc}
\hline Pertanyaan butir kuesioner CACT versi Indonesia & \multicolumn{2}{c}{ Corrected item-total correlation ( $r)$} \\
\cline { 2 - 3 } & $\begin{array}{c}\text { Nilai yang tidak } \\
\text { distandarisasi }\end{array}$ & $\begin{array}{c}\text { Nilai yang } \\
\text { distandarisasi }(z \text { score })\end{array}$ \\
\hline 1. Bagaimana asma kamu hari ini? & 0,479 & 0,464 \\
2. Apakah asma kamu terasa mengganggu saat berlari, senam atau & 0,489 & 0,494 \\
$\quad \begin{array}{l}\text { berolahraga? } \\
\text { 3. Apakah kamu batuk karena asma kamu? }\end{array}$ & 0,518 & 0,528 \\
4. Apakah kamu terbangun di malam hari karena asma kamu? & 0,539 & 0,563 \\
5. Dalam 4 minggu terakhir, berapa hari anak anda menunjukkan gejala & 0,493 & 0,490 \\
asma pada siang hari? & 0,384 & 0,377 \\
6. Dalam 4 minggu terakhir, berapa hari anak anda mengalami napas berbunyi \\
$\begin{array}{l}\text { ngik-ngik (atau mencicit/mencuit) di siang hari karena asma? } \\
\text { 7. Dalam 4 minggu terakhir, berapa hari anak anda terbangun di malam } \\
\text { hari karena asma? }\end{array}$ & 0,545 & 0,544 \\
\hline
\end{tabular}

Dari 66 subjek, ketidaksesuaian hasil CACT dengan nilai $\mathrm{FEV}_{1}$ cukup besar $(53 \%)$ yaitu terdapat 15 pasien dengan skor CACT $>19$, tetapi memiliki hasil FEV $1<80 \%$. Sebaliknya, 20 pasien dengan skor CACT $\leq 19$, tetapi memiliki hasil FEV $1 \geq 80 \%$. Demikian pula tidak didapatkan korelasi bermakna antara CACT versi Indonesia dengan variabilitas mingguan PEF ( $r=-$ 0,218; $\mathrm{p}=0,079)$ (Gambar 2).

\section{Pembahasan}

Sampai saat ini, tidak ada satu baku emas pengukuran atau penilaian terkendalinya asma. Status terkendalinya asma mencakup empat komponen yang terlibat pada definisi asma, yaitu gejala klinis, obstruksi saluran napas, hiperreaktivitas bronkus, dan inflamasi saluran napas. Keempat komponen di atas berkaitan lemah sehingga tidak satupun komponen tunggal yang dapat menggambarkan tingkat terkendalinya asma. Oleh sebab itu, sampai saat ini, belum ada satupun baku emas penilaian terkendalinya asma. ${ }^{7}$

Kuesioner CACT versi bahasa Inggris sebagai salah satu alat penilaian terkendalinya asma sudah terbukti kesahihan dan keandalannya. Kelebihan kuesioner CACT ini adalah adanya visualisasi gambar sehingga lebih mudah dimengerti oleh anak usia muda. Penerapan klinis penggunaan kuesioner untuk penyakit 
asma di Indonesia tidaklah semudah pada negara lain. Indonesia memiliki beragam bahasa lokal terhadap kata/istilah asma dan pemahaman penyakit asma pada masyarakat Indonesia juga masih kurang. Merujuk pada hal tersebut, pengisian CACT sebaiknya tetap dilakukan dengan pendampingan dokter atau orangtua yang mengerti pemahaman asma dengan baik.

Uji keandalan kuesioner CACT versi bahasa Indonesia dilakukan dengan penilaian internal konsistensi melalui uji Cronbach's $\alpha$ (pada nilai tidak terstandarisasi maupun terstandarisasi dengan nilai $z$-score). Hasil uji Cronbach's $\alpha$ terbukti andal (Cronbach's $\alpha>0,7$ ) dan serupa dengan hasil penelitian Chen $\mathrm{dkk}^{8}$ (Cronbach's $\alpha 0,741$ ) pada uji keandalan Chinnese-CACT. Dua penelitian uji keandalan kuesioner CACT terjemahan di atas mempunyai keandalan serupa dengan CACT dalam bahasa aslinya, yaitu pada penelitian Liu dkk ${ }^{4}$ (Cronbach's $\alpha=0,79$ ) dan Shi dkk9 (Cronbach's $\alpha=0,76$ ).

Penilaian kesahihan kuesioner CACT versi bahasa Indonesia adalah kesahihan interna (konstruksi) dan kesahihan eksterna (kriteria). Nilai r yang dapat diterima dalam penilaian kesahihan interna suatu kuesioner adalah 0,3. Baik di Indonesia maupun di luar negeri, belum ada baku emas untuk mengukur tingkat kendali asma. Kesahihan konstruksi terbukti baik dengan hasil $r$ berkisar antara 0,384-0,545. Penelitian Liu $\mathrm{dkk}^{4}$ menunjukkan hasil serupa yaitu uji kesahihan konstruksi CACT berkisar 0,41-0,68.

Pada uji kesahihan eksterna (kriteria), tidak terdapat korelasi antara kuesioner CACT versi Indonesia dengan pemeriksaan objektif uji fungsi paru. Korelasi antara CACT dan $\% \mathrm{FEV}_{1}$ dari penelitian lainnya mendapatkan hasil bervariasi. Beberapa penelitian melaporkan korelasi bermakna, walaupun dengan nilai korelasi (r) lemah, seperti pada penelitian Green $\mathrm{dkk}^{10}$ (kappa 0,24), Waibel $\mathrm{dkk}^{11}$ yang menggunakan kuesioner modifikasi CACT berbahasa Jerman $(r=0,36$; $\mathrm{p}<0,000)$, dan Piacentini dkk ${ }^{12}(\mathrm{r}=0,34 ; \mathrm{p}=0,022) \mathrm{pa}-$ da pasien asma yang belum mendapat tata laksana adekuat sesuai panduan GINA. Namun, pada kelompok pasien yang sudah mendapat tata laksana adekuat sesuai panduan GINA, Piacentini ${ }^{12}$ melaporkan korelasi tidak bermakna. Penyebab korelasi tidak bermakna yang dikemukakan adalah adanya disosiasi antara perbaikan gejala klinis dengan normalisasi pemeriksaan objektif $\left(\mathrm{FEV}_{1}\right)$ pasca-tata laksana adekuat. Pada penelitian ini, tidak dilakukan analisis tentang tata laksana yang sebelumnya telah didapatkan sehingga tidak dapat dibedakan lebih mendalam seperti pada penelitian Piacentini.

Korelasi tidak bermakna juga dilaporkan pada penelitian lain, yaitu penelitian $\mathrm{Yu} \mathrm{dkk}^{13}(\mathrm{r}=0,15$; $\mathrm{p}=0,22)$ dan Wildhaber $\mathrm{dkk}^{14}(\mathrm{r}=-0,22 ; \mathrm{p}=0,34)$. Wildhaber menyatakan nilai $\mathrm{FEV}_{1}$ tunggal mempunyai keterbatasan karena hanya menggambarkan obstruksi pada saluran napas besar sehingga merekomendasikan penggunaan variabel lain pada spirometri yang juga menggambarkan kondisi saluran napas kecil

Ketidaksesuaian antara penilaian CACT dengan FEV cukup besar (53\%). Sebesar 30,3\% mempunyai skor CACT $\leq 19$, tetapi nilai $F E V \geq 80 \%$. Penyebab skor klinis yang rendah, tetapi uji fungsi paru normal dilaporkan oleh Bacharier. ${ }^{15}$ Bacharier melaporkan pada kelompok asma persistenpun mayoritas anak mempunyai nilai $\mathrm{FEV}_{1}$ normal. Penyebab lain adalah penggunaan obat pengendali steroid inhalasi. Steroid inhalasi umumnya membuat perbaikan bermakna dalam uji fungsi paru, tetapi tidak sepenuhnya menghilangkan gejala klinis hiperreaktivitas bronkus. ${ }^{15,16}$ Adanya komorbiditas seperti sinusitis dan rinitis alergika juga dapat menyebabkan perburukan gejala asma tanpa menyebabkan terjadinya penurunan uji fungsi paru. ${ }^{17}$ Penelitian ini tidak melakukan analisis data tersebut sehingga kedua penyebab di atas masih mungkin terjadi.

Sebaliknya, penyebab uji fungsi paru yang rendah, tetapi skor klinis yang normal juga dapat terjadi. Pada penelitian ini, terdapat $22,7 \%$ mempunyai CACT $>19$, tetapi nilai $\mathrm{FEV}_{1}<80 \%$. Hasil serupa dilaporkan oleh Verini dkk, ${ }^{16}$ 28\% dan Eid dkk ${ }^{18} 43 \%$. Verini ${ }^{16}$ menjelaskan adanya obstruksi saluran napas masih dapat terjadi, walaupun tanpa gejala klinis bermakna (subklinis), sedangkan Eid $^{18}$ menyatakan obstruksi napas kronis dapat membuat anak beradaptasi sehingga menyebabkan persepsi yang salah mengenai derajat terkendalinya asma. Penyebab di atas dapat terjadi pada penelitian ini, melihat data proporsi usia subjek dengan skor CACT terkendali, tetapi mempunyai nilai $\mathrm{FEV}_{1}$ di bawah normal mayoritas 9 tahun ke atas.

Keterbatasan lain penilaian $\mathrm{FEV}_{1}$ adalah nilai referensi $\mathrm{FEV}_{1}$. Nilai referensi $\mathrm{FEV}_{1}$ berbeda sesuai etnik sehingga idealnya yang digunakan sebagai referensi adalah nilai $\mathrm{FEV}_{1}$ sesuai usia untuk anak Indonesia, tetapi sampai saat ini belum ada nilai referensi tersebut.

Tidak didapatkan korelasi yang tidak bermakna antara hasil variabilitas mingguan PEF dengan skor 
CACT. Peneliti tidak mendapatkan penelitian lain yang membandingkan kuesioner dengan hasil variabilitas, tetapi membandingkan secara langsung dengan nilai PEF tunggal. Penelitian Chen $\mathrm{dkk}^{8}(\mathrm{r}=-0,02 ; \mathrm{p}=0,756)$ dan Chan $\mathrm{dkk}^{19}\left(\mathrm{r}^{2}=0,0032\right)$ melaporkan korelasi yang tidak bermakna antara C-CACT dengan nilai prediksi PEF. Chan menyimpulkan fungsi saluran napas dan gejala subjektif yang dirasakan oleh pasien merupakan 2 alat yang independent dalam mengevaluasi terkendalinya asma.

Proporsi asma tidak terkendali berdasarkan penilaian kuesioner CACT versi bahasa Indonesia cukup tinggi, yaitu $60,6 \%$. Hasil ini serupa dengan survei tingkat asma tidak terkendali oleh Dean $\mathrm{dkk}^{20}$ terhadap 473 orangtua pasien asma berusia 6-12 tahun sebesar 76,1\%. Liu dkk ${ }^{21}$ melaporkan prevalensi tidak terkendalinya asma berdasarkan kuesioner CACT orisinal sebesar 46\%, sedangkan survei oleh Asthma Insights and Reality in the Asia-Pacific (AIRIAP 2) ${ }^{22}$ melaporkan tingkat tidak terkendalinya asma anak di wilayah Asia masih tinggi, yaitu 53,4\%. Beberapa penyebab prevalensi asma tidak terkendali yang tinggi adalah pemberian terapi tidak sesuai panduan GINA, pengetahuan orangtua tentang gejala asma yang kurang, komorbiditas penyakit seperti rinitis atau sinusitis yang dapat membuat perburukan asma, serta paparan yang sering terhadap pencetus asma seperti asap rokok. ${ }^{22}$

\section{Kesimpulan}

Kuesioner CACT versi Indonesia mempunyai keandalan dan kesahihan interna yang baik sehingga dapat dipakai untuk menilai tingkat terkendalinya asma pada anak berusia 4-11 tahun. Walaupun demikan, tidak dapat menggantikan peran uji fungsi paru sebagai salah satu komponen penilaian terkendalinya asma. Hal ini dapat disebabkan karena gejala klinis dengan tanda obstruksi paru hanya berkaitan lemah dan menggambarkan komponen yang berbeda dalam penyakit asma.

\section{Daftar pustaka}

1. Global Initiative for Asthma. Global strategy for asthma management and prevention. 2008. (Diakses pada 3 September 2009). Diunduh dari: http://www.ginanasthma. com/ Guidelineitem. asp $l 1=2$ b $l 2=1$ erintId $=1561$.

2. Liu AH, Covar RA, Spahn JD, Leung DM. Childhood asthma. Dalam: Berhman RE, Kliegman RM, Jensen $\mathrm{HB}$, penyunting. Nelson textbook of pediatric. Edisi ke-18. Philadelphia: WB Saunders Company; 2007. h. 953-69.

3. Yawn BP, Brenneman SK, Allen-Ramey FC, Cabana MD, Markson LE. Assessment of asthma severity and asthma control in children. Pediatrics 2006;118:322-7.

4. Liu AH, Zeiger R, Sorkness C, Mahr T, Ostrom N, Burgess $S$, dkk. Development and cross-sectional validation of the childhood asthma control test. J Allergy Clin Immunol 2007;119:817-25.

5. World Health Organization. Process of translation and adaptation of instruments. (Diakses pada 1 Februari 2011). Diunduh dari: http://www. research_tools/translation/en/.

6. Praptiwi A. Prevalens asma pada anak SMP di Jakarta Pusat berdasarkan angket modifikasi ISAAC yang diuji (tesis). Jakarta: Universitas Indonesia; 1997.

7. American Thoracic Society Documents. An official American Thoracic Society/ European Respiratory Society statement: Asthma control and exacerbations. Standardizing endpoints for clinical asthma trials and clinical practice. American J Respir Crit Care Med 2009;180:60-71.

8. Chen HH, Wang JY, Jan RL, Liu YH, Liu LF. Reliability and validity of childhood asthma control test in a population of Chinese asthmatic children. Qual Life Res 2008; 17:585-93.

9. Shi Y, Tatavoosian AV, Aledia AS, George SC, Galant SP. Cut points for asthma control tests in Mexican children in Orange Country California. Ann Allergy Asthma Immunol 2012;109:108-13.

10. Green RJ, Halkas A, Kitchin O, Masekela RL. Disagreement among common measures of asthma control in children. Chest 2013;143:117-22.

11. Waibel V, Ulmer H, Horak E. Assessing asthma control: symptom scores, GINA levels of asthma control, lung function, and exhaled nitric oxide. Pediatr Pulmonol 2012;47:113-8.

12. Piacentini GL. Peroni DG, Bodini A, Bonafiglia E, Rigotti E, Baraldi E dkkl. Childhood asthma control test and airway inflammation evaluation in asthmatic children. Allergy 2009;64:1753-7.

13. Yu HR, Niu CK, Kuo HC, Tsui KY, Wu CC, Ko CH, dkk. Comparison of the Global Initiative for Asthma guideline-based asthma control measure and the childhood asthma control test in evaluating asthma control in children. Pediatric Neonatol 2010;51:273-8. 
14. Wildhaber JH, Sznitman J, Harpes P, Straub D, Möller A, Basek P dkk. Correlation of spirometry and symptom scores in childhood asthma and the usefulness of curvature assessment in expiratory flow-volume curves. Respir Care 2007;52:1744-52.

15. Bacharier LB, Strunk RC, Mauger D, White D, Lemanske RF, Sorkness CA. Classifying asthma severity in children: Mismatch between symptoms, medication use, and lung function. Am J Respir Crit Care Med 2004;176:426-32.

16. Verini M, Rossi N, Dalfino T, Verrotti A, Di Gioacchino M, Chiarrelli F. Lack of correlation between clinical patterns of asthma and airway obstruction. Allergy Asthma Proc 2001;22:297-302.

17. Dixon AE, Kaminsk y DA, Holbrook JT, Wise RA, Shade DM, Irvin CG. Allergic rhinitis and sinusitis in asthma:differential effects on symptoms and pulmonary function. Chest 2006;130:429-35.

18. Eid N, Yandell B, Howell L, Eddy M, Sheikh S. Can peak expiratory flow predict airflow obstruction in children with asthma? Pediatrics 2000;105:354-8.

19. Chan M, Sitaraman S, Dosanjh A. Asthma control test and peak expiratory flow rate: Independent pediatric asthma management tools. J Asthma 2009;46:1042-4.

20. Dean BB, Calimlim BC, Sacco P, Aguilar A, Maykut R, Tinkelman D. Uncontrolled asthma: assessing quality of life and productivity of children and their caregivers using a cross-sectional internet-based survey. Health Qual Life Outcomes 2010;8:1-10.

21. Liu AH, Gilsenan AW, Stanford RH, Lincourt W, Ziemiecki R,Ortega H. Status of asthma control in pediatric primary care: Results from the pediatric asthma control characteristics and prevalence survey study (ACCESS). J Pediatr 2010;157:276-81.

22. Wong GWK, Kwon N, Hong JG, Hsu JY, Gunasekera KD. Pediatric asthma control in Asia: Phase 2 of the asthma insights and reality in Asia-Pacific (AIRIAP 2) survey. Allergy 2013;68:524-30. 